\title{
ALTERAÇÕES DAS CARACTERÍSTICAS QUÍMICAS DE TRÊS SUBSTRATOS COMERCIAIS NA PRODUÇÃO DE MUDAS CÍTRICAS
}

\author{
Change of the chemical characteristics of three commercial substrates in the production of citric seedlings
}

\author{
Mário Luís Fochesato ${ }^{1}$, Paulo Vitor Dutra de Souza², Gilmar Schäfer ${ }^{3}$, Hardi Schmatz Maciel ${ }^{1}$
}

\begin{abstract}
RESUMO
Avaliou-se a dinâmica dos nutrientes em três substratos comerciais em que cultivaram-se mudas cítricas, desde o momento da repicagem dos porta-enxertos até a fase final de produção das mesmas. O experimento foi conduzido em ambiente protegido, sendo as mudas cultivadas em citropotes de 4L. O experimento foi desenvolvido na Estação Experimental Agronômica da UFRGS em Eldorado do Sul, RS, no período de junho/2003 a novembro/2004, e obedeceu ao delineamento experimental de blocos casualizados, em esquema fatorial $3 \times 3 \times 2$, sendo: 3 substratos comerciais de cultivo (Comercial 1, 2 e 3 - composto de turfa preta; cascas processadas e enriquecidas, perlita, vermiculita expandida e turfa; e, casca de pinus compostada e vermiculita, respectivamente), 3 porta-enxertos (Trifoliata - Poncirus trifoliata [L.] Raf.; citrangeiro 'C13' - Citrus sinensis [L.] Osbeck x P. trifoliata [L.] Raf.; e limoeiro 'Cravo' - C. limonia Osbeck) e 2 variedades copa (laranjeira 'Valência'-C. sinensis [L.] Osbeck e a tangerineira 'Montenegrina' - C. deliciosa Tenore). Empregou-se o sistema de irrigação por gotejamento. Avaliou-se a caracterização química dos substratos e conteúdo nutricional foliar e a massa seca da raiz e da parte aérea. Nas condições deste experimento, os substratos apresentam perdas consideráveis de nutrientes, especialmente de fósforo e potássio. No entanto, observa-se que o substrato Comercial 2 apresenta maior aporte de nutrientes, quando comparado com os outros substratos, proporcionando maior acúmulo de massa seca nos porta-enxertos, no momento da enxertia e nas mudas cítricas no final do experimento.
\end{abstract}

Termos para indexação: Ambiente protegido, nutrição, propagação, Citrus spp., Poncirus sp.

\section{ABSTRACT}

The dynamics of nutrients in three commercial substrates were evaluated, from the transplanting until final nursery. The rootstocks were cultivated in $4 \mathrm{~L}$ containers under greenhouse conditions. The experiment was developed at Estação Experimental Agronômica of UFRGS from June/2003 to November/2004, with the experimental design of completely randomized blocks, in factorial $3 \times 3 \times 2$, where 3 commercial substrates were tested (Commercial 1, 2 and 3 - composed of black turf; processed and enriched barks, perlite, vermiculite expanded and turf; and, composted pine bark and vermiculite, respectively), 3 citrus rootstocks (Trifoliate orange - Poncirus trifoliata [L.] Raf.; 'C13' citrange-Citrus sinensis [L.] Osbeck x P. trifoliata [L.] Raf.; and 'Rangpur' lime - C. limonia Osbeck) and 2 citrus varieties ('Valencia'-C. sinensis [L.] Osbeck and the 'Montenegrina' mandarin - C. deliciosa Tenore). One evaluated the substrate chemical characterization and foliar nutritional content and dry mass content of the rootstock. The substrates showed significant reductions in the concentration of nutrients, specially phosphorus and potassium. However, one observed that the Commercial 2 substrate presents greater port of nutrients when compared to the other substrates, providing larger accumulation of dry mass in the rootstocks at grafting time and final nursery production.

Index terms: Greenhouse, nutrition, propagation, Citrus spp., Poncirus sp.

(Recebido em 17 de maio de 2006 e aprovado em 29 de janeiro de 2008)

\section{INTRODUÇÃO}

A muda é o principal investimento na implantação de um pomar. Segundo Porto et al. (1995), quase 50\% do investimento, no primeiro ano, é com a aquisição de mudas. Apesar do seu alto custo, a qualidade fitossanitária é fundamental, pois junto com a muda, o citricultor pode estar comprando uma série de problemas, como doenças e pragas que serão introduzidas em seu pomar e no dos vizinhos, como cancro cítrico, clorose variegada dos citros
(CVC), minador das folhas dos citros e viroses (SCHÄFER, 2004). Além dessas, fungos de solo (como a gomose Phytophthora spp.) e nematóides podem ser introduzidos com o uso de substratos contaminados. Por ser uma cultura perene, a qualidade da muda é a chave para o sucesso ou o fracasso na implantação do pomar.

Na produção de mudas em recipientes, o substrato deve possibilitar o desenvolvimento das raízes e servir como suporte para as plantas, principalmente nos seus

\footnotetext{
'Engenheiros Agrônomos, Mestres - Departamento de Horticultura e Silvicultura/DHS - Universidade Federal do Rio Grande do Sul/UFRGS - Avenida Bento Gonçalves, 7712 - Agronomia - Cx. P. 15100 - 91501-970 - Porto Alegre, RS - mariofochesato@ig.com.br; hardimaciel@yahoo.com.br 'Engenheiro Agrônomo, Professor Associado - Departamento de Horticultura e Silvicultura/DHS, PPGFitotecnia, Faculdade de Agronomia - Universidade Federal do Rio Grande do Sul/UFRGS - Avenida Bento Gonçalves, 7712 - Cx. P. 15100 - 91501-970 - Porto Alegre, RS - Bolsista CNPQ - pvdsouza@ufrgs.br ${ }^{3}$ Engenheiro Agrônomo, Doutor - Departamento de Horticultura e Silvicultura/DHS - Universidade Federal do Rio Grande do Sul/UFRGS - Avenida Bento Gonçalves, 7712 - Agronomia - Cx. P. 15100 - 91501-970 - Porto Alegre, RS - gilmarschafer@hotmail.com
} 
estádios iniciais. Para um melhor desenvolvimento delas, torna-se necessário conhecer a qualidade do substrato utilizado, através de suas características químicas (FERMINO, 1996).

As características químicas mais importantes nos substratos compreendem o valor do $\mathrm{pH}$, a capacidade de troca de cátions, a condutividade elétrica e/ou teor total de sais solúveis e seus níveis nutricionais (FERMINO, 1996).

A utilização de substratos mais específicos para cada cultura, possibilita encurtar o período de formação da muda, mediante as condições ambientais e dos tratos culturais realizados. Atualmente, no Brasil existem poucos substratos comerciais direcionados para a cultura de citros em recipientes, sendo importante determinar a dinâmica dos nutrientes ao longo do cultivo, e sua relação com o desenvolvimento da muda. Nesse sentido, objetivou-se, no presente trabalho, avaliar o comportamento dos nutrientes contidos nos três substratos comerciais, desde o momento da repicagem dos porta-enxertos até a fase de muda pronta em ambiente protegido.

\section{MATERIAL E MÉTODOS}

O experimento foi realizado em casa de vegetação, situada no setor de Horticultura da Estação Experimental Agronômica da Universidade Federal do Rio Grande do Sul (EEA/UFRGS), em Eldorado do Sul, RS. O mesmo foi executado no período de junho de 2003 até novembro de 2004, compreendendo 17 meses, ou seja, envolvendo desde o período de repicagem dos porta-enxertos dos tubetes para os citropotes até a muda pronta para o comércio.

O delineamento experimental adotado foi o de blocos casualizados, em esquema fatorial, testando-se três fatores ( $3 \times 3 \times 2)$, que foram: três substratos comerciais (Comercial 1, Comercial 2 e Comercial 3), 3 porta-enxertos (Trifoliata-Poncirus trifoliata [L.] Raf.; citrangeiro 'C13' - Citrus sinensis [L.] Osbeck x P. trifoliata [L.] Raf.; e limoeiro 'Cravo' - C. limonia Osbeck) e duas variedades copa (laranjeira 'Valência' - C. sinensis [L.] Osbeck e a tangerineira 'Montenegrina' $-C$. deliciosa Tenore). O experimento foi executado em 3 blocos, sendo que cada bloco foi composto de 18 tratamentos; e cada parcela apresentou oito plantas.

Os substratos comerciais apresentavam as seguintes composições: Comercial 1 (composto de turfa preta), Comercial 2 (composto de cascas processadas e enriquecidas, perlita, vermiculita expandida e turfa) e Comercial 3 (composto de casca de pinus compostada e vermiculita).
Neste trabalho, foram utilizados porta-enxertos produzidos em casa de vegetação em tubetes cônicos (tamanho 3 x $12 \mathrm{~cm}$ - volume de $50 \mathrm{~cm}^{3} /$ tubete). Eles foram padronizados pela altura, em torno de $10 \mathrm{~cm}$, e/ou pelo desenvolvimento radicular completo. Os mesmos foram repicados para os citropotes (tamanho $15 \times 35 \mathrm{~cm}$ - volume de $4000 \mathrm{~cm}^{3} /$ citropote), devidamente enchidos com os substratos comerciais. Os citropotes consistiram de vasos de plástico rígido, que apresentavam, internamente, estrias longitudinais para direcionar o crescimento das raízes, evitando o enovelamento. Esses foram destinados à produção de mudas cítricas.

A irrigação foi feita diariamente, mediante gotejamento, em torno de duas a três vezes ao dia, com duração de cinco a dez minutos cada. Os maiores períodos foram utilizados em condições de alta temperatura (verão) e os menores períodos em baixa temperatura (inverno), no interior da casa de vegetação. Cada gotejador apresentou uma vazão de 1,65 $\mathrm{L} \mathrm{hora}^{-1}$. A fertilização foi via água de irrigação, com uma solução nutritiva completa elaborada na EEA/UFRGS (SCHAFER, 2004), numa concentração de $400 \mathrm{mg} \mathrm{L}^{-1}$. Nos três últimos meses (agosto, setembro e outubro/2004), na fase de muda pronta, foi realizada uma aplicação superficial de nitrogênio na forma de uréia (quando o substrato estava umedecido), além de duas aplicações, do mesmo adubo, via fertirrigação, ambas na dose de 1,35 $\mathrm{g} \mathrm{N}$ planta $^{-1}$.

Para as análises químicas dos substratos, as amostras foram coletadas em três estádios. O primeiro estádio, no momento da repicagem dos porta-enxertos nos citropotes; o segundo, no momento da enxertia desses porta-enxertos; e o terceiro, no final do experimento, ou seja, quando as mudas estavam prontas para o comércio.

Para a determinação do $\mathrm{pH}$ coletou-se, no primeiro estádio, uma amostra de cada substrato, oriunda do mesmo lote de chegada. No segundo e terceiro estádios, apanhouse uma amostra de cada substrato dentro de cada bloco (linha de irrigação), oriunda da mistura de cada substrato, depois da retirada dos mesmos dos citropotes.

Para a avaliação das demais características químicas, coletou-se uma amostra de cada substrato, para cada estádio. No primeiro estádio (no início do cultivo), as amostras foram obtidas dentro do mesmo lote de chegada, e no segundo e terceiro, as amostras foram oriundas de uma mistura desses mesmos substratos, retirados anteriormente na caracterização de $\mathrm{pH}$, retirando o efeito do bloco, avaliando-se somente o fator substrato.

Os seguintes parâmetros foram avaliados: 1) Caracterização química dos substratos e conteúdo nutricional foliar, seguindo-se a metodologia descrita por 
Tedesco et al. (1995), com os seguintes itens: carbono orgânico (C.O.), capacidade de troca de cátions (CTC), macronutrientes e o valor de $\mathrm{pH}$ em água; 2) Massa seca da raiz e da parte aérea, em gramas, obtidas pela secagem em estufa, com temperatura de $65^{\circ} \mathrm{C}$, até peso constante (TEDESCO et al., 1995).

A análise estatística compreendeu a análise de variância e as médias foram submetidas ao teste de Tukey, ao nível de 5\% de significância.

\section{RESULTADOS E DISCUSSÃO}

No momento da enxertia dos porta-enxertos, os valores de $\mathrm{pH}$ foram elevados, provavelmente em decorrência do alto $\mathrm{pH}$ da água utilizada na irrigação (Tabela 1). No final do experimento, o pH dos três substratos sofreu leve redução, devido à adubação nitrogenada (complementada pela uréia). O substrato Comercial 2 apresentou menor $\mathrm{pH}$ do que os outros substratos, pois ele também era menor no início do experimento. Quando se utiliza substrato orgânico, sem solo, segundo Kämpf (2000), o pH desses deve estar na faixa de 5,2 a 5,5; enquanto, Bailey et al. (2005a,b) recomendam de 5,4 a 6,2, para a maioria das culturas. Nesse sentido, observa-se, que no momento da repicagem dos porta-enxertos, todos os substratos comerciais estavam na faixa recomendável.

Os valores de CTC encontraram-se acima do valor de referência $\left(12 \mathrm{cmol} \cdot \mathrm{dm}^{-3}\right)$ para substratos, estabelecidos por Penningsfeld (1978) (Tabela 1). Este pesquisador estabelece que teores de matéria orgânica (M.O.) de 50\% são ideais para substratos, que representam $25 \%$ de carbono orgânico (C.O.). Sendo assim, o substrato Comercial 1 apresentou valores altos, sendo que, na fase final do experimento, houve um aumento do C.O., quando se esperaria uma redução; dessa forma, provavelmente, esse aumento deveu-se à desuniformidade dentro do próprio substrato, apesar de ter sido misturado no momento da retirada da amostra. Já o substrato Comercial 2 apresentou valores próximos ao estabelecido pelo pesquisador anteriormente citado. Enquanto, o Comercial 3 apresentou uma maior degradação de sua M.O. no final do experimento, resultando em baixo teor de carbono orgânico.

Segundo as recomendações da Comissão de Química e Fertilidade do Solo - RS e SC (2004), todos os substratos apresentavam níveis de macronutrientes muito altos no momento da repicagem. O teor de fósforo permaneceu muito alto durante o experimento no substrato Comercial 2; no Comercial 3, permaneceu em níveis médios, sendo que o substrato Comercial 1 chegou ao final com um teor muito baixo desse nutriente. O potássio apresentou uma maior redução, decaindo do nível alto para o muito baixo no substrato Comercial 1 e baixo no Comercial 3, enquanto que, para o substrato Comercial 2, chegou ao nível médio, já que possuía 2,7 e 2,0 vezes mais que o Comercial 1 e o Comercial 3, respectivamente. Os teores de cálcio e de magnésio permaneceram altos, durante os estágios avaliados. O enxofre passou do nível alto ao médio, para os substratos Comercial 1 e Comercial 2, e de alto ao baixo, no Comercial 3.

Tabela 1 - Características químicas dos substratos em diferentes estádios do experimento, mantidos em citropotes, e em casa de vegetação. EEA/UFRGS, Eldorado do Sul, 2003/2004.

\begin{tabular}{|c|c|c|c|c|c|c|c|c|c|}
\hline \multirow{3}{*}{ Substratos } & \multirow{3}{*}{ Estádios } & \multirow{3}{*}{$\begin{array}{c}\text { pH } \\
\text { em água }\end{array}$} & \multirow{2}{*}{ C.O. ${ }^{1}$} & \multicolumn{6}{|c|}{ Teores de macronutrientes } \\
\hline & & & & $\mathrm{P}^{2}$ & $\mathrm{~K}^{3}$ & $S^{4}$ & $\mathrm{Ca}^{5}$ & $\mathrm{Mg}^{6}$ & $\mathrm{CTC}^{7}$ \\
\hline & & & $\%$ & \multicolumn{3}{|c|}{-------mg dm $\mathrm{mg}^{-3}-------$} & \multicolumn{3}{|c|}{------ $\mathrm{cmol}_{\mathrm{c}} \mathrm{dm}^{-3}$} \\
\hline \multirow{3}{*}{ Comercial 1} & Repicagem & 6,1 & -8 & 117,0 & 274,0 & 11,0 & 30,6 & 6,1 & 41,0 \\
\hline & Enxertia & 7,0 & 32,0 & 9,4 & 28,9 & 6,6 & 21,1 & 4,7 & 25,8 \\
\hline & Final & 6,7 & 36,0 & 4,9 & 28,9 & 2,7 & 19,4 & 4,6 & 24,0 \\
\hline \multirow{3}{*}{ Comercial 2} & Repicagem & 5,4 & - & 350,0 & 742,0 & 20,0 & 25,0 & 9,5 & 40,3 \\
\hline & Enxertia & 6,8 & 26,0 & 169,8 & 118,0 & 4,6 & 15,1 & 3,8 & 19,2 \\
\hline & Final & 6,4 & 23,0 & 50,8 & 76,0 & 2,7 & 14,0 & 3,5 & 17,7 \\
\hline \multirow{3}{*}{ Comercial 3} & Repicagem & 5,7 & - & 271,0 & 364,0 & 19 & 11,7 & 10,7 & 26,9 \\
\hline & Enxertia & 7,2 & 25,0 & 63,9 & 36,9 & 6,5 & 11,8 & 4,9 & 16,8 \\
\hline & Final & 6,8 & 20,0 & 20,0 & 27,5 & 1,6 & 9,7 & 3,8 & 13,6 \\
\hline
\end{tabular}

${ }^{1}$ Carbono orgânico, ${ }^{2}$ Fósforo, ${ }^{3}$ Potássio, ${ }^{4}$ Enxofre, ${ }^{5}$ Cálcio, ${ }^{6}$ Magnésio, ${ }^{7}$ Capacidade de troca de cátions, ${ }^{8}$ Dado não avaliado inicialmente. 
Após 17 meses desse experimento, os nutrientes que diminuíram seus teores no substrato foram o fósforo e o potássio. No substrato Comercial 1, essa diminuição representou cerca de $95,8 \%$ para o fósforo e $89,45 \%$, para o potássio. No Comercial 2, 85,49\% e $89,75 \%$, respectivamente e, no Comercial 3, 92,62\% e 92,45\% (Tabela 1). A perda de nutrientes pela lixiviação é um sério problema no sistema de produção de mudas, em ambiente protegido, pois representa uma perda de capital, na forma de nutrientes e de água, além do risco de contaminação ambiental. Portanto, deve-se considerar que cada substrato exige um manejo diferenciado da irrigação e fertilização utilizadas.

Apesar da diminuição da concentração de nutrientes nos substratos pela absorção pelas plantas, lixiviação e adsorção, no final do experimento a maior parte dos nutrientes $(\mathrm{P}, \mathrm{S}, \mathrm{Ca}$ e $\mathrm{Mg}$ ) ainda encontrava-se em níveis altos. Esses altos teores devem-se à suplementação química estabelecida pelos fabricantes e pela fertirrigação realizada ao longo do experimento e/ou às diferentes fontes de nutrientes presentes em determinados materiais constituintes dos substratos.

Apesar da maior quantidade de nutrientes presentes no substrato Comercial 2, no momento da repicagem dos porta-enxertos (Tabela 1), observa-se que não houve diferenças significativas nos teores de nitrogênio, fósforo e potássio presentes na massa seca dos porta-enxertos cultivados nos três substratos.

Os porta-enxertos demonstraram diferenças na absorção de nitrogênio, e o Trifoliata apresentou maior concentração comparativamente aos demais, que não diferiram entre si. Apesar das diferenças, todos os níveis são considerados normais (Tabela 2). A absorção de fósforo (níveis normais), cálcio (níveis insuficientes) e magnésio (níveis normais) não demonstraram diferenças significativas nos três porta-enxertos utilizados.

O porta-enxerto limoeiro 'Cravo' absorveu mais potássio, estando esse em excesso, seguido pelo citrangeiro ' $\mathrm{C} 13$ ', enquanto o porta-enxerto Trifoliata teve uma menor resposta na absorção desse nutriente, no entanto ambos apresentaram níveis normais (Tabela 2). O mesmo comportamento foi obtido por Schäfer (2004), nas condições de viveiro, com uma maior absorção de potássio pelo porta-enxerto limoeiro 'Cravo', seguido pelo 'C13', com o Trifoliata absorvendo menos potássio.

Apesar dos níveis altos de cálcio nos substratos, no momento da repicagem (Tabela 1), observa-se que o conteúdo de cálcio, em todos os tratamentos foi insuficiente (Tabela 2). Isso se deve a um forte antagonismo entre $\mathrm{K} / \mathrm{Ca}$ e $\mathrm{Mg} / \mathrm{Ca}$, ou seja, onde há altos teores de um dos elementos, há inibição na absorção do outro (MALAVOLTA \& VIOLANTE NETO, 1989).

Como resposta no conteúdo de massa seca, as plantas produzidas no substrato Comercial 2 sobressaíramse às demais com maior quantidade de massa seca nas raízes, na parte aérea e no total (Tabela 2). Esse maior acúmulo de massa seca é explicado pelo maior aporte de nutrientes presentes inicialmente no substrato Comercial 2, quando comparado com os outros substratos (Tabela 1).

Os porta-enxertos citrangeiro ' $\mathrm{C} 13$ ' e limoeiro 'Cravo' apresentaram semelhante acúmulo de massa seca nas raízes, que foram superiores ao do Trifoliata (Tabela 2). Na parte aérea, o porta-enxerto citrangeiro ' $\mathrm{C} 13$ ' foi

Tabela 2 - Concentração de macronutrientes presentes na massa seca das folhas e massa seca das raízes, da parte aérea e total dos porta-enxertos na fase de enxertia, produzidos em diferentes substratos. EEA/UFRGS, Eldorado do Sul, 2003/2004.

\begin{tabular}{|c|c|c|c|c|c|c|c|c|}
\hline \multirow{3}{*}{$\begin{array}{l}\text { Tratamentos } \\
\text { Substratos }\end{array}$} & \multicolumn{5}{|c|}{ Macronutrientes na massa seca das folhas } & \multicolumn{3}{|c|}{ Massa seca } \\
\hline & $\mathrm{N}^{1}$ & $\mathrm{P}^{2}$ & $\mathrm{~K}^{3}$ & $\mathrm{Ca}^{4}$ & $\mathrm{Mg}^{5}$ & Raiz & Parte aérea & Total \\
\hline & \multicolumn{5}{|c|}{ 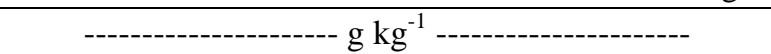 } & \multicolumn{3}{|c|}{--------- g planta ${ }^{-1}$--------- } \\
\hline Comercial 1 & 26,5 & 1,59 & 19,21 & $21,01 \mathrm{a}^{6}$ & $3,31 \mathrm{~b}$ & $2,95 \mathrm{~b}$ & $4,14 \mathrm{~b}$ & $7,09 \mathrm{~b}$ \\
\hline Comercial 2 & 25,49 & 1,92 & 19,49 & $16,46 \mathrm{~b}$ & $2,67 \mathrm{c}$ & $6,79 \mathrm{a}$ & $16,02 \mathrm{a}$ & $22,81 \mathrm{a}$ \\
\hline Comercial 3 & 25,01 & 1,89 & 19,1 & $16,74 \mathrm{~b}$ & $4,63 \mathrm{a}$ & $3,46 \mathrm{~b}$ & $5,57 \mathrm{~b}$ & $9,03 \mathrm{~b}$ \\
\hline \multicolumn{9}{|l|}{ Porta-enxertos } \\
\hline Trifoliata & $28,27 \mathrm{a}$ & 1,83 & $16,41 \mathrm{c}$ & 16,7 & 3,73 & $2,37 \mathrm{~b}$ & $4,90 \mathrm{~b}$ & $7,27 \mathrm{c}$ \\
\hline ‘Cravo' & $24,42 \mathrm{~b}$ & 1,72 & $21,56 \mathrm{a}$ & 18,11 & 3,43 & $4,87 \mathrm{a}$ & $7,63 \mathrm{~b}$ & $12,51 \mathrm{~b}$ \\
\hline 'C13' & $24,31 \mathrm{~b}$ & 1,85 & $19,83 \mathrm{~b}$ & 19,41 & 3,45 & $5,96 \mathrm{a}$ & $13,20 \mathrm{a}$ & $19,15 \mathrm{a}$ \\
\hline $\mathrm{CV}(\%)$ & 9,04 & 16,16 & 6,19 & 13,07 & 10,04 & 25,50 & 37,20 & 31,60 \\
\hline
\end{tabular}

${ }^{1}$ Nitrogênio, ${ }^{2}$ Fósforo, ${ }^{3}$ Potássio, ${ }^{4}$ Cálcio, ${ }^{5}$ Magnésio, ${ }^{6}$ Médias seguidas por letras diferentes e minúsculas na coluna, em cada fator, diferem entre si pelo teste de Tukey, em nível de $5 \%$ de probabilidade de erro. 
superior aos demais, que não diferiram entre si. No total, o porta-enxerto citrangeiro ' $\mathrm{C} 13$ ' apresentou maior quantidade de massa seca, seguido pelo limoeiro 'Cravo' $\mathrm{e}$ Trifoliata, como conseqüência do ocorrido na parte aérea. A menor massa seca apresentada pelo Trifoliata, em parte pode ser explicada, por tratar-se de um porta-enxerto de caráter caducifólio, que em resposta às temperaturas amenas, reduz drasticamente sua atividade metabólica e vigor (LEITE JUNIOR, 1992).

A análise estatística somente revelou o efeito isolado dos substratos, dos porta-enxertos e das variedades copa, no conteúdo de macronutrientes presentes na massa seca das folhas e na massa seca da raiz, parte aérea e total das variedades copa, na fase de muda pronta (Tabela 3).

As mudas produzidas nos substratos Comercial 2 e Comercial 3 apresentaram teores semelhantes entre si de nitrogênio, cálcio e magnésio, os quais mostraram-se superiores ao das mudas produzidas no substrato Comercial 1 (Tabela 3). Os teores de fósforo foram maiores nas mudas produzidas no substrato Comercial 2, seguidos pelos das produzidas no substrato Comercial 3, com menores teores nas produzidas no substrato Comercial 1. As mudas produzidas no substrato Comercial 2 apresentaram teores de potássio superiores ao daquelas produzidas nos substratos Comercial 3 e Comercial 1, os quais não diferiram significativamente entre si.
As mudas enxertadas sobre limoeiro 'Cravo' e citrangeiro ' $\mathrm{C} 13$ ' apresentaram teores de macronutrientes semelhantes entre si e superiores aos das plantas enxertadas sobre o Trifoliata. Entre as variedades copa, somente houve variação significativa nos teores de potássio, que foram maiores na laranjeira 'Valência' (Tabela 3).

Os valores de "referência" para os teores foliares da cultura de citros recomendados pela Comissão de Química e Fertilidade do Solo - RS e SC (2004) indicam que os teores de nitrogênio apresentaram-se excessivos nas mudas produzidas nos substratos Comercial 2 e Comercial 3 , comparativamente aos das produzidas no substrato Comercial 1, que apresentaram teores insuficientes. As mudas produzidas no substrato Comercial 2 apresentaram níveis excessivos de fósforo e de potássio; enquanto nas produzidas no substrato Comercial 3 foram normais. As mudas produzidas no substrato Comercial 1 tiveram teores insuficientes de fósforo e normais de potássio. Esse comportamento pode ser explicado pela análise química final dos substratos (Tabela 1), em que o nível de fósforo estava alto no substrato Comercial 2, médio no Comercial 3 , enquanto no substrato Comercial 1 era muito baixo, e, para o potássio, o substrato Comercial 2 apresentava nível médio e no Comercial 3 e Comercial 1 nível baixo e muito baixo.

Os porta-enxertos limoeiro 'Cravo' e citrangeiro 'C13', independente da cultivar copa enxertada,

Tabela 3 - Concentração de macronutrientes presentes na massa seca das folhas e a massa seca das raízes, da parte aérea e total da variedade copa na fase de muda pronta, produzidos em diferentes substratos, no interior da casa de vegetação. EEA/UFRGS, Eldorado do Sul, 2003/2004.

\begin{tabular}{|c|c|c|c|c|c|c|c|c|}
\hline \multirow{2}{*}{ Tratamentos } & \multicolumn{5}{|c|}{ Macronutrientes na massa seca das folhas } & \multicolumn{3}{|c|}{ Massa seca } \\
\hline & $\mathrm{N}^{1}$ & $\mathrm{P}^{2}$ & $\mathrm{~K}^{3}$ & $\mathrm{Ca}^{4}$ & $\mathrm{Mg}^{5}$ & Raiz & Parte aérea & Total \\
\hline Substratos & \multicolumn{5}{|c|}{---------------------- $\mathrm{g} \mathrm{kg}^{-1}$------------------- } & \multicolumn{3}{|c|}{--------- g planta $^{-1}$--------- } \\
\hline Comercial 1 & $21,74 b^{6}$ & $0,97 \mathrm{c}$ & $12,35 \mathrm{~b}$ & $14,26 \mathrm{~b}$ & $1,77 \mathrm{~b}$ & $5,10 \mathrm{~b}$ & $5,46 \mathrm{~b}$ & $10,52 \mathrm{~b}$ \\
\hline Comercial 2 & $36,90 \mathrm{a}$ & $2,10 \mathrm{a}$ & $20,61 \mathrm{a}$ & $19,95 \mathrm{a}$ & $2,43 \mathrm{a}$ & $9,23 \mathrm{a}$ & $13,77 \mathrm{a}$ & $23,00 \mathrm{a}$ \\
\hline Comercial 3 & $30,64 \mathrm{a}$ & $1,49 \mathrm{~b}$ & $14,73 \mathrm{~b}$ & $17,12 \mathrm{a}$ & $2,26 \mathrm{a}$ & $6,30 \mathrm{~b}$ & $6,73 \mathrm{~b}$ & $13,03 \mathrm{~b}$ \\
\hline \multicolumn{9}{|l|}{ Porta-enxertos } \\
\hline Trifoliata & $17,48 \mathrm{~b}$ & $1,00 \mathrm{~b}$ & $8,96 \mathrm{~b}$ & $7,46 \mathrm{~b}$ & $1,40 \mathrm{~b}$ & $2,54 \mathrm{c}$ & $2,20 \mathrm{c}$ & $4,74 \mathrm{c}$ \\
\hline 'Cravo' & $36,10 \mathrm{a}$ & $1,61 \mathrm{a}$ & $20,08 \mathrm{a}$ & $21,08 \mathrm{a}$ & $2,37 \mathrm{a}$ & $7,99 \mathrm{~b}$ & $8,91 \mathrm{~b}$ & $16,90 \mathrm{~b}$ \\
\hline 'C13' & $35,69 \mathrm{a}$ & $1,77 \mathrm{a}$ & $18,65 \mathrm{a}$ & $22,80 \mathrm{a}$ & $2,70 \mathrm{a}$ & $10,05 \mathrm{a}$ & $14,85 \mathrm{a}$ & $24,90 \mathrm{a}$ \\
\hline \multicolumn{9}{|l|}{ Variedades copa } \\
\hline 'Montenegrina' & 28,93 & 1,51 & $14,02 \mathrm{~b}$ & 17,13 & 2,00 & 6,23 & $7,40 \mathrm{~b}$ & $13,63 \mathrm{~b}$ \\
\hline 'Valência' & 30,58 & 1,41 & $17,77 \mathrm{a}$ & 17,10 & 2,32 & 7,49 & $9,90 \mathrm{a}$ & $17,39 \mathrm{a}$ \\
\hline $\mathrm{CV}(\%)$ & 25,97 & 29,08 & 25,91 & 27,25 & 31,71 & 17,74 & 22,45 & 22,09 \\
\hline
\end{tabular}

${ }^{1}$ Nitrogênio, ${ }^{2}$ Fósforo, ${ }^{3}$ Potássio, ${ }^{4}$ Cálcio, ${ }^{5}$ Magnésio, ${ }^{6}$ Médias seguidas por letras diferentes e minúsculas na coluna, em cada fator, diferem entre si pelo teste de Tukey, a $5 \%$ de probabilidade de erro. 
apresentaram teores de nitrogênio excessivos, de fósforo normais e de potássio normais a excessivos, enquanto no porta-enxerto Trifoliata os três nutrientes foram insuficientes (Tabela 3). Ao contrário do observado na fase de enxertia (Tabela 2), onde o Trifoliata apresentou níveis normais de nitrogênio, fósforo e potássio, essa diferença provavelmente se deva às variedades copa utilizadas. A absorção desses nutrientes pelo Trifoliata teve alta correlação na massa seca total (Tabela 3$)(\mathrm{N}: \mathrm{r}=0,93, \mathrm{P}$ : $\mathrm{r}=0,90$ e $\mathrm{K}: \mathrm{r}=0,91$, todos com coeficiente de Pearson $<0,001)$, ou seja, a baixa absorção desses nutrientes pelo porta-enxerto resultou num menor desenvolvimento vegetativo, que, como conseqüência, apresentou menor acúmulo de massa seca total.

Em relação ao fator variedade copa, tanto a laranjeira 'Valência', quanto a tangerineira 'Montenegrina' apresentaram teores próximos ao excessivo de nitrogênio e teores normais de fósforo e potássio (Tabela 3).

Em geral, o nitrogênio apresentou teores muito elevados na maior parte dos tratamentos avaliados, provavelmente isso deve-se à aplicação adicional de uréia, que não precisaria ter sido realizada, com exceção para o substrato Comercial 1 e o porta-enxerto Trifoliata. Isso demonstra que a absorção nutricional de cada variedade de porta-enxerto é distinta, portanto a adubação e os níveis nutricionais dos substratos devem ser planejados conforme a variedade produzida.

Todos os substratos, no final do experimento, ainda apresentavam altos conteúdos de cálcio e de magnésio (Tabela 1). Entretanto, observa-se que a absorção deles para todos os tratamentos foi insuficiente, com exceção do magnésio, nas plantas enxertadas sobre o porta-enxerto citrangeiro ' $\mathrm{C} 13$ ', que foi normal. Como descrito na tabela 2 , provavelmente houve uma forte inibição competitiva entre os nutrientes, em que a planta absorveu mais potássio durante o cultivo, o que dificultou a assimilação do cálcio e do magnésio (MALAVOLTA \& VIOLANTE NETO, 1989).

Assim, os substratos induziram diferentes respostas no acúmulo de massa seca na raiz, na parte aérea e no total, em que os maiores valores foram obtidos com a utilização do substrato Comercial 2, enquanto os outros substratos apresentaram um comportamento semelhante entre si, com menor quantidade de massa seca na raiz, parte aérea e total (Tabela 3). O mesmo comportamento foi observado na tabela 2, na fase de enxertia. Os substratos Comercial 1 e Comercial 3 possuíam menor aporte de nutrientes, desde o momento da repicagem (Tabela 1), fato que pode explicar esses resultados.
O porta-enxerto citrangeiro ' $\mathrm{C} 13$ ' apresentou maior acúmulo de massa seca na raiz, na parte aérea e no total, seguido pelo porta-enxerto limoeiro 'Cravo' (Tabela 3). O porta-enxerto Trifoliata teve baixa resposta na massa seca acumulada na raiz, na parte aérea e no total. O porta-enxerto Trifoliata teve o mesmo comportamento conforme observase na Tabela 2.

As variedades copa não influíram sobre a massa seca de suas raízes (Tabela 3). No entanto, as mesmas apresentaram diferenças significativas na massa seca da parte aérea e, em consequiência, na massa seca total, a laranjeira 'Valência' possibilitou um maior acúmulo de massa seca na parte aérea e total, comparativamente à tangerineira 'Montenegrina'.

\section{CONCLUSÕES}

O substrato Comercial 2 (composto de cascas processadas e enriquecidas, perlita, vermiculita expandida e turfa) apresentou maior aporte de nutrientes quando comparado com os outros substratos, proporcionando maior acúmulo de massa seca nos porta-enxertos e nas mudas cítricas, diferindo estatisticamente dos demais.

\section{REFERÊNCIAS BIBLIOGRÁFICAS}

BAILEY, D. A.; FONTENO, W. C.; NELSON, P. V. Greenhouse substrates and fertilization. Raleigh: North Caroline State University, 2005a. Disponível em: <http:// Www.ces.ncsu.edu/depts/hort/floriculture/plugs ighsubfert.pdf? Acesso em: 1 fev. 2005.

BAILEY, D. A.; NELSON, P. V.; FONTENO, W. C. Substrate pH and water quality. Raleigh: North Caroline State University, 2005b. Disponível em: <http:// Lwww.ces.ncsu.edu/depts/hort/floriculture/plugs/ph.pdf Acesso em: 1 fev. 2005.

COMISSÃO DEQUÍMICAEFERTILIDADEDO SOLO_RS E SC. Manual de adubação e de calagem para os Estados do Rio Grande do Sul e de Santa Catarina. 10. ed. Porto Alegre, 2004. 400 p.

FERMINO, M. H. Aproveitamento de resíduos industriais e agrícolas como alternativas de substratos hortícolas. 1996. 90 f. Dissertação (Mestrado Fitotecnia) Universidade Federal do Rio Grande do Sul, Porto Alegre, 1996.

KÄMPF, A. N. Produção comercial de plantas ornamentais. Guaíba: Agropecuária, 2000. 254 p. 
LEITE JUNIOR, R. P. Cultivares de copa e porta-enxertos. In: IAPAR. A citricultura no Paraná. Londrina, 1992. p. 91-116. (Circular, 72).

MALAVOLTA, E.; VIOLANTE NETTO, A. Nutrição mineral, calagem, gessagem e adubação dos citros. Piracicaba: Associação Brasileira para Pesquisa da Potassa e do Fosfato, 1989. 153 p.

PENNINGSFELD, F. Substrates for protected cropping. Acta Horticulturae, Wageningen, n. 82, p. 13-22, 1978.
PORTO, O. de M. et al. Recomendações técnicas para a cultura de citros no Rio Grande do Sul. Porto Alegre: Fepagro, 1995. 78 p. (Boletim técnico Fepagro, 3).

SCHÄFER, G. Produção de porta-enxertos cítricos em recipientes e ambiente protegido no Rio Grande do Sul. 2004. 129 f. Tese (Doutorado Fitotecnia) - Universidade Federal do Rio Grande do Sul, Porto Alegre, 2004.

TEDESCO, M. J.; GIANELLO, C.; BISSANI, C. A. Análise de solo, plantas e outros materiais. 2. ed. Porto Alegre: UFRGS, 1995. 174 p. 